\title{
Investigating the relationship between the long-term exposure to air pollution and the frequency of depression in Shiraz during 2010-2017
}

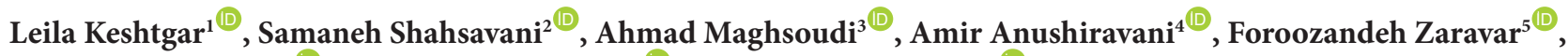 \\ Narges Shamsedini ${ }^{2,6^{\mathbb{D}}}$, Maryam Rayatpisheh $^{2^{*}(\mathbb{D})}$, Mansooreh Dehghani $^{1^{*}(\mathbb{D})}$
}

${ }^{1}$ Research Center for Health Sciences, Department of Environmental Health Engineering, School of Health, Shiraz University of Medical Sciences, Shiraz, Iran

${ }^{2}$ Research Center for Health Sciences, Department of Environmental Health Engineering, School of Health, Student Research Committee, Shiraz University of Medical Sciences, Shiraz, Iran

${ }^{3}$ Research Center for Health Sciences, Department of Epidemiology, School of Health, Shiraz University of Medical Sciences, Shiraz, Iran

${ }^{4}$ Digestive Disease Research Institute, Shariati Hospital, Tehran University of Medical Sciences, Tehran, Iran

${ }^{5}$ Research Center for Health Sciences, School of Paramedical Sciences, Shiraz University of Medical Sciences, Shiraz, Iran

Committee, Shiraz University of Medical Sciences, Shiraz, Iran

${ }^{6}$ Fars Water and Wastewater Company

\begin{abstract}
Background: Exposure to environmental pollutants which have entered the atmosphere due to human and industrial activities results in harmful and unwanted effects on human health. The undesired effects of air pollution on mental disorders, mortality, and psychological disorders have been proven. Depression is a common mental health problem in today's societies which impacts the quality of life. The objective of this study was to determine the relation between exposure to air pollution and frequency of depression in Shiraz (Southern Iran).

Methods: Archived documents of 2658 patients diagnosed with major depressive disorder (MDD) from a psychiatric university hospital were reviewed. The concentrations of five air pollutants including $\mathrm{CO}$, $\mathrm{NO}_{\mathrm{X}}, \mathrm{O}_{3}, \mathrm{PM}_{10}$, and $\mathrm{NO}_{2}$ were determined daily in two air quality monitory stations in downtown Shiraz (Imam Hossein Square) and Kazeroon Gate. The data relevant to these five pollutants were gathered every day for 83 months, from 2010 to 2017, and for more precision, the mean values were used. The relationship between the concentration of each pollutant in the air and the number of patients referring to hospital was determined using the Spearman's correlation coefficient.

Results: There was a direct and significant relationship between all pollutants and the number of hospital admissions in each month $(P<0.05)$ except for $\mathrm{CO}$ which did not show a significant relationship with hospital admission due to depression $(P>0.05)$.

Conclusion: The results of this study indicated a positive relationship between air pollution and depression. Of course, to prove this relationship, it is essential to conduct a number of studies with appropriate methodology and design.

Keywords: Air pollutant, Environmental exposure, Inhalation exposure, Mental disorders, Depression Citation: Keshtgar L, Shahsavani S, Maghsoudi A, Anushiravani A, Zaravar F, Shamsedini N, et al. Investigating the relationship between the long-term exposure to air pollution and the frequency of depression in shiraz during 2010-2017. Environmental Health Engineering and Management Journal 2021; 8(1): 9-14. doi: 10.34172/EHEM.2021.02.
\end{abstract}

\section{Introduction}

Different kinds of pollutants enter the atmosphere from natural resources or due to human and industrial activities $(1,2)$, and exposure to each of these pollutants can result in unwanted and harmful effects on human health (36). Different studies illustrated that air pollution can significantly increase the risk of respiratory disease (79), cardiovascular events (10), cancer, stroke, and type 2 diabetes mellitus (11). Moreover, the adverse effects of air pollution on brain disorders and mortality have been proved (12).

Depression is a common mental health problem in 
today's societies which impacts the quality of life and has a significant burden on healthcare systems. Although depression is one of the main reasons for committing suicide, medications and non-psychological diseases such as stroke, diabetes, and cancer can be the attributing factors $(4,13,14)$. Epidemiological studies have shown a relationship between air pollution and depression symptoms in humans $(15,16)$.

In a study by Zijlema et al, a significant relation between $\mathrm{NO}_{\mathrm{x}}$ and depression was determined (3). Joubert et al proved that depression symptoms and atmospheric pollution increase the risk of stroke (4). In a study by Vert et al on long and short-term exposure to air pollutants and also anger and depression, it was indicated that the increase in pollutant concentration increases anger and depression symptoms (12). Cho et al studied the relationship between air pollution, depression and heart disease and showed that increasing $\mathrm{PM}_{10}, \mathrm{SO}_{2}, \mathrm{NO}_{2}$, and $\mathrm{CO}$ concentration enhances depression symptoms effectively and significantly (13). In the research by Lamers et al in the USA, it was determined that long and short-term exposure to air pollution increases the stress symptoms that are mostly accompanied by depression (17).

Since the air quality in metropolitan cities such as Shiraz is declining over time and many studies have emphasized the relationship between air pollution and diseases and given that limited epidemiological studies have been performed to evaluate these issues in Middle Eastern countries, this study aims to determine the relationship between depression and exposure to air pollutants in Shiraz (as a developing and industrialized metropolis (, Iran from 2010 to 2017.

\section{Materials and Methods \\ Study design and population}

This cross-sectional study was conducted on 2658 patients diagnosed with major depressive disorder (MDD) based on the criteria proposed by Diagnostic and Statistical Manual of Mental Disorders (DSM-IV-TR) (American Psychiatric Association, 2000). The data were collected from patient documents in a psychiatric university hospital in South of Iran, from April 2010 to February 2017. Informed consent was obtained from all participants and from the parents of the participants under 18 years of age.

The inclusion criteria were (a) having normal cognition, (b) being 16-87 years old, and (c) being diagnosed with MDD by a faculty psychiatrist. The exclusion criteria were (a) being of a cognitive performance that falls outside the established cut-offs, and having (b) significant diseases that could interfere with cognition, (c) severe auditory, visual, neurodevelopmental, and/or psychomotor disorders, (d) brain injury, and (e) other major active psychiatric disorders according to the criteria proposed by DSM-IV-TR (American Psychiatric Association, 2000), including schizophrenia, dementia, or bipolar disorders.
All methods were carried out in accordance with relevant guidelines and regulations and all experimental protocols were approved by Ethics Committee of Shiraz University of Medical Sciences.

\section{Air pollution assessment}

This was a cross-sectional study. The concentrations of five air pollutants including $\mathrm{CO}, \mathrm{NO}_{\mathrm{X}}, \mathrm{O}_{3}, \mathrm{PM}_{10}$, and $\mathrm{NO}_{2}$ were determined daily in two air quality monitory stations in downtown Shiraz (Imam Hossein Square) and Kazeroon Gate. These stations are under the supervision of the Environmental Health Organization. The data regarding these five pollutants were gathered every day for 83 months, between 2010 and 2017, and for more precision, their mean values were used.

Quality control was conducted by duplicate samples methods. For this method, two out of every few samples were taken side by side using the same procedures and tested separately and analyzed in the same procedure.

\section{Statistical analysis}

The normal distribution of air pollutants and the number of hospital visits were examined before analyzing the data using the Kolmogorov-Smirnov test. The results of this test showed that none of the variables had a normal distribution $(P<0.05)$. The mean value of each air pollutant per month as well as the number of patients in that month were available. As a result, the Spearman's correlation coefficient was used to determine the relationship between the concentration of each pollutant in the air and the number of patients that referred to hospital (data on the number of patients and the concentration of air pollutants did not have a normal distribution and Spearman's correlation coefficient was used).

One of the limitations of the present study was that only data on the mean of each air pollutant and the number of depressive patient admissions were available monthly and the access to other information (such as confounders) was limited.

\section{Results}

\section{Population characteristics}

A total of 2364 depression cases were recorded during 3636 days from 2010-2017, of which 1551 cases (65.60\%) were men and 813 cases $(34.40 \%)$ were women. The average age of the participants was $38.85 \pm 13.67$.

\section{Air pollution and depression}

This was the first study to investigate the relationship between long-term exposure to air pollution and depression in Shiraz. The data regarding air pollution from April 22, 2010 to March 20, 2017 and the number of hospital admissions due to depression were evaluated. Annual mean concentration of air pollutants and total number of depression hospital admissions are presented in Table 1 and Figure 1. 


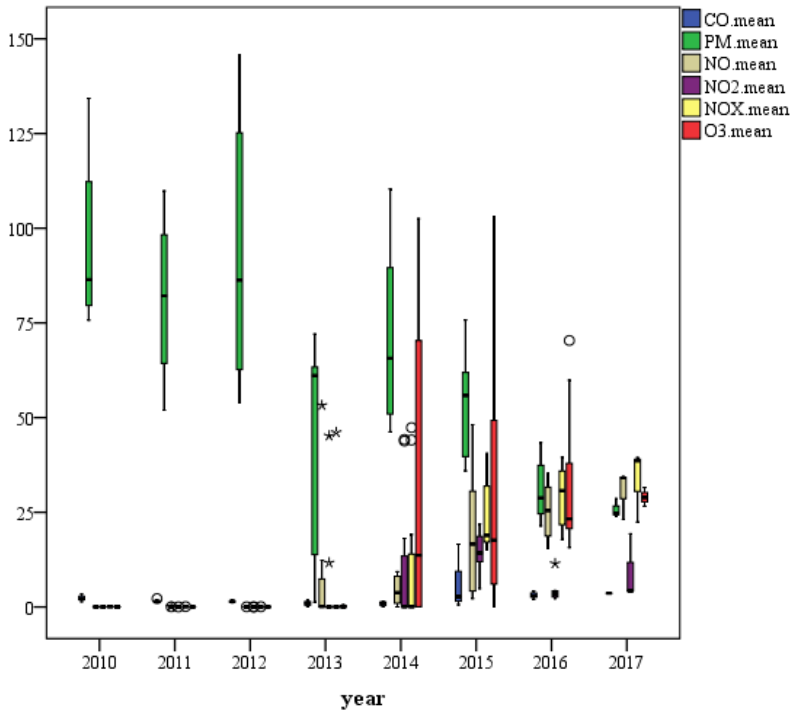

Figure 1. Annual mean concentration of air pollutants in Shiraz (2010-2017).

As it is depicted in Table 1, the mean concentration of $\mathrm{PM}_{10}$ and $\mathrm{NO}_{\mathrm{x}}$ increased from 2010 to 2017. The mean concentration of $\mathrm{CO}$ and $\mathrm{O}_{3}$ increased until 2015 and then decreased.

The correlation coefficient between the concentration of air pollutants and the number of hospital admissions due to depression in each month in Shiraz are presented in Table 2.

The results revealed that all pollutants had a direct and significant relationship with the number of hospital admissions in each month $(P<0.05)$ except $\mathrm{CO}$ which did not have a significant relationship with hospital admissions due to depression $(P>0.05)$. On the other hand, as the mean value of pollutants increased each month (except CO), the number of hospital admissions due to depression also increased.

\section{Discussion}

Some studies in Seoul, Canada and United State emphasize the relationship between air pollution and depression in different countries $(13,16,18,19)$. In the study by Vert et al, the investigation of the effect of longterm exposure to air pollution on stress and depression showed that the increase in the level of air pollutants had a direct and positive relationship with depression. Their results indicated that there was a higher possibility of depression with increasing exposure to $\mathrm{NO}_{\mathrm{X}}, \mathrm{NO}_{2}, \mathrm{PM}_{10}$, and $\mathrm{O}_{3}$, which is similar to the results of the present study (12). Another study on American women showed that the increase in $\mathrm{O}_{3}$ and $\mathrm{PM}_{10}$ increased depression (20). A research done in China showed that increasing $\mathrm{PM}_{2.5}$ concentration caused enhancement of symptoms of depression. It is noticeable that neighborhood and social capital decreased the negative effects of $\mathrm{PM}_{2.5}$ on depression symptoms among examined persons (21). Various studies have described different biological reasons for this issue. More air pollution can increase the risk of cardiovascular effects and these diseases are related to depression symptoms $(22,23)$. Therefore, residents of cities with more air pollution have higher risks of cardiovascular diseases and depression, thus, there was observed a relationship between air pollution, depression symptoms, and cardiovascular effects. Besides, air pollution can decrease physical activities and sports in polluted outdoors and consequently results in depression symptoms (21-24). Moreover, air pollution biologically

Table 1. Mean concentration and standard deviation of air pollutants in Shiraz (2010-2017)

\begin{tabular}{|c|c|c|c|c|c|c|c|}
\hline \multirow{2}{*}{ Year } & \multirow{2}{*}{ Number } & \multicolumn{6}{|c|}{ Pollutants } \\
\hline & & O3 (ppm) & NOX (ppm) & NO2 (ppm) & NO (ppm) & $\mathrm{PM}_{10}\left(\mu \mathrm{g} / \mathrm{m}^{3}\right)$ & $\mathrm{CO}$ (ppm) \\
\hline 2010 & 23 & $0.02(0.008)$ & $0.08(0.02)$ & $0.02(0.001)$ & $0.04(0.01)$ & 99.67 (32.23) & $2.31(0.63)$ \\
\hline 2011 & 18 & $0.02(0.008)$ & $0.06(0.01)$ & $0.02(0.003)$ & $0.03(0.01)$ & $80.90(19.32)$ & $1.55(0.27)$ \\
\hline 2012 & 167 & $0.02(0.008)$ & $0.05(0.01)$ & $0.02(0.003)$ & $0.03(0.008)$ & $92.44(32.88)$ & $1.45(0.23)$ \\
\hline 2013 & 415 & $0.16(0.02)$ & $3.89(13.28)$ & $4.76(13.16)$ & $6.79(15.30)$ & $44.53(27.80)$ & $0.95(0.56)$ \\
\hline 2014 & 492 & $33.39(43.21)$ & 9.99 (17.66) & $9.61(16.98)$ & $4.57(3.67)$ & $70.72(23.84)$ & $0.86(0.49)$ \\
\hline 2015 & 568 & $32.76(37.43)$ & $24.13(9.31)$ & $14.98(4.81)$ & 18.79 (15.58) & $52.54(13.20)$ & $5.66(5.69)$ \\
\hline 2016 & 556 & $31.30(17.91)$ & $29.09(8.20)$ & $3.98(2.47)$ & $25.34(7.49)$ & $30.70(7.77)$ & $3.07(0.67)$ \\
\hline 2017 & 125 & $29.02(2.44)$ & $33.48(9.55)$ & 9.25 (8.69) & $30.52(6.40)$ & $25.75(2.47)$ & $3.61(0.03)$ \\
\hline
\end{tabular}

Dare are expressed as mean (standard deviation).

Table 2. Correlation coefficient between concentration of air pollutants and number of hospital admissions due to depression in each month in Shiraz

\begin{tabular}{|c|c|c|c|c|c|c|c|}
\hline & & \multicolumn{6}{|c|}{ Pollutant } \\
\hline & & $\mathrm{CO}$ (ppm) & O3 (ppm) & NOX (ppm) & NO2 (ppm) & NO (ppm) & $\mathrm{PM}\left(\mu \mathrm{g} / \mathrm{m}^{3}\right)$ \\
\hline \multirow{2}{*}{$\begin{array}{l}\text { Hospital } \\
\text { visit }\end{array}$} & Correlation coefficient & 0.129 & 0.715 & 0.494 & 0.660 & 0.652 & 0.564 \\
\hline & $P$ value & 0.246 & 0.001 & 0.001 & 0.001 & 0.001 & 0.001 \\
\hline
\end{tabular}


may decrease sunlight that may be a stressor for residents' nervous system that results in depression (25-27). Some studies have shown that air pollution can decrease faceto-face social contact among neighbors, therefore, the danger of depression enhances (28-30). In a study by Cho et al. a positive and significant relationship was reported between $\mathrm{SO}_{2}, \mathrm{PM}_{10}, \mathrm{NO}_{2}$, and $\mathrm{CO}$ and admission to Seoul hospital for depression. They announced that $\mathrm{PM}_{10}$ might induce dopamine neuron damage causing changes in neurotransmitter levels via an inflammatory process (13). Moreover, in a cohort study on South Korean adults, it was proved that long-term exposure to air pollutants such as $\mathrm{PM}_{10}$ and $\mathrm{NO}_{2}$ increases suicide due to depression (31). Indeed, inhalation of PM can activate pro-inflammatory cytokines in human macrophages, initiating an inflammatory response and inducing oxidative stress (32-36). Eventually, oxidative stress and systemic inflammation can cause depression and anxiety behaviors $(37,38)$. Dorado-Martínez et al demonstrated that $\mathrm{O}_{3}$ can act as an oxidative stress factor and finally results in brain damage and sudden severe depression symptoms which can lead to committing suicide (39). Nevertheless, some studies show different results. For example, the results of a study in Canada showed that the relationship between air pollution and depression in people over 65 years old was not significant (19). But, some study shows there are relationship between air pollution and other disease such as cardiovascular disease (7).

\section{Limitations and strengths}

In this study, a large and representative dataset was evaluated for a long period of time. The study was restricted to analyze cases referring to the emergency department (ED) that were acute and relatively severe. This data also reflects where symptoms were initiated or exacerbated, therefore, it was limited compared to other types of medical care.

ED cases for depressive episodes might have various psychiatric symptoms other than depression such as anxiety, suicidal ideation, and psyhosis, and it is possible that air pollution might trigger those conditions as well. Patients might have had other comorbidities which were not documented.

\section{Conclusion}

The present study showed a significant and effective relationship between air pollution and the possibility of depression. Nonetheless, in order to prove the causal relationship between air pollution and depression, further researches with suitable methods are required.

\section{Acknowledgments}

The authors would like to thank the Vice-Chancellor for Research of Shiraz University of Medical Sciences for financially supporting the research (No. 17854).

\section{Ethical issues}

All methods were carried out in accordance with relevant guidelines and regulations and all experimental protocols were approved by Ethics Committee of Shiraz University of Medical Sciences. This research has been approved by the Ethics Committee of Shiraz University of Medical Sciences, Iran (number: ir.sums.rec.1393.8095)

\section{Competing interests}

The authors declare that they have no competing interests.

\section{Authors' contributions}

Data collection, analysis, and interpretation were accomplished by contribution of all authors, and the authors reviewed, revised, and approved the manuscript as well.

\section{References}

1. Shahsavani S, Dehghani M, Hoseini M, Fararouei M. Biological monitoring of urinary 1-hydroxypyrene by PAHs exposure among primary school students in Shiraz, Iran. Int Arch Occup Environ Health 2017; 90(2): 179-87. doi: 10.1007/s00420-016-1184-9.

2. Shahsavani S, Hoseini M, Dehghani M, Fararouei M. Characterisation and potential source identification of polycyclic aromatic hydrocarbons in atmospheric particles (PM(10)) from urban and suburban residential areas in Shiraz, Iran. Chemosphere 2017; 183: 557-64. doi: 10.1016/j.chemosphere.2017.05.101.

3. Zijlema WL, Wolf $\mathrm{K}$, Emeny R, Ladwig $\mathrm{KH}$, Peters A, Kongsgård $\mathrm{H}$, et al. The association of air pollution and depressed mood in 70,928 individuals from four European cohorts. Int J Hyg Environ Health 2016; 219(2): 212-9. doi: 10.1016/j.ijheh.2015.11.006.

4. Joubert J, Cumming TB, McLean AJ. Diversity of risk factors for stroke: the putative roles and mechanisms of depression and air pollution. J Neurol Sci 2007; 262(1-2): 71-6. doi: 10.1016/j.jns.2007.06.027.

5. Adam M, Schikowski T, Carsin AE, Cai Y, Jacquemin B, Sanchez M, et al. Adult lung function and long-term air pollution exposure. ESCAPE: a multicentre cohort study and meta-analysis. Eur Respir J 2015; 45(1): 38-50. doi: 10.1183/09031936.00130014.

6. Shahsavani S, Dehghani M, Hoseini M, Fararouei M. Health Risk assessment of atmospheric particulate-bound polycyclic aromatic hydrocarbons in Shiraz, Iran. J Air Pollut Health 2016; 1(3): 153-60.

7. Dehghani M, Anushiravani A, Hashemi H, Shamsedini N. Survey on air pollution and cardiopulmonary mortality in shiraz from 2011 to 2012: an analytical-descriptive study. Int J Prev Med 2014; 5(6): 734-40.

8. Dehghani M, Fazlzadeh M, Sorooshian A, Tabatabaee HR, Miri M, Norouzian Baghani A, et al. Characteristics and health effects of BTEX in a hot spot for urban pollution. Ecotoxicol Environ Saf 2018; 155: 133-43. doi: 10.1016/j. ecoenv.2018.02.065.

9. Dehghani M, Keshtgar L, Javaheri MR, Derakhshan Z, Oliveri Conti G, Zuccarello P, et al. The effects of 
air pollutants on the mortality rate of lung cancer and leukemia. Mol Med Rep 2017; 15(5): 3390-7. doi: 10.3892/ mmr.2017.6387.

10. Beelen R, Stafoggia M, Raaschou-Nielsen O, Andersen ZJ, Xun WW, Katsouyanni K, et al. Long-term exposure to air pollution and cardiovascular mortality: an analysis of 22 European cohorts. Epidemiology 2014; 25(3): 368-78. doi: 10.1097/ede.0000000000000076.

11. Sun Q, Hong X, Wold LE. Cardiovascular effects of ambient particulate air pollution exposure. Circulation 2010; 121(25): 2755-65. doi: 10.1161/circulationaha.109.893461.

12. Vert C, Sánchez-Benavides G, Martínez D, Gotsens X, Gramunt N, Cirach M, et al. Effect of long-term exposure to air pollution on anxiety and depression in adults: a crosssectional study. Int J Hyg Environ Health 2017; 220(6): 1074-80. doi: 10.1016/j.ijheh.2017.06.009.

13. Cho J, Choi YJ, Suh M, Sohn J, Kim H, Cho SK, et al. Air pollution as a risk factor for depressive episode in patients with cardiovascular disease, diabetes mellitus, or asthma. J Affect Disord 2014; 157: 45-51. doi: 10.1016/j. jad.2014.01.002.

14. Tzivian L, Winkler A, Dlugaj M, Schikowski T, Vossoughi $\mathrm{M}$, Fuks K, et al. Effect of long-term outdoor air pollution and noise on cognitive and psychological functions in adults. Int J Hyg Environ Health 2015; 218(1): 1-11. doi: 10.1016/j.ijheh.2014.08.002.

15. Lim YH, Kim H, Kim JH, Bae S, Park HY, Hong YC. Air pollution and symptoms of depression in elderly adults. Environ Health Perspect 2012; 120(7): 1023-8. doi: 10.1289/ ehp. 1104100 .

16. Szyszkowicz M, Rowe BH, Colman I. Air pollution and daily emergency department visits for depression. Int J Occup Med Environ Health 2009; 22(4): 355-62. doi: 10.2478/v10001-009-0031-6.

17. Lamers F, van Oppen P, Comijs HC, Smit JH, Spinhoven $\mathrm{P}$, van Balkom AJ, et al. Comorbidity patterns of anxiety and depressive disorders in a large cohort study: the Netherlands Study of Depression and Anxiety (NESDA). J Clin Psychiatry 2011; 72(3): 341-8. doi: 10.4088/ JCP.10m06176blu.

18. Kioumourtzoglou MA, Power MC, Hart JE, Okereke OI, Coull BA, Laden F, et al. The association between air pollution and onset of depression among middle-aged and older women. Am J Epidemiol 2017; 185(9): 801-9. doi: 10.1093/aje/kww163.

19. Szyszkowicz M. Air pollution and emergency department visits for depression in Edmonton, Canada. Int J Occup Med Environ Health 2007; 20(3): 241-5. doi: 10.2478/ v10001-007-0024-2.

20. Wang Y, Eliot MN, Koutrakis P, Gryparis A, Schwartz JD, Coull BA, et al. Ambient air pollution and depressive symptoms in older adults: results from the MOBILIZE Boston study. Environ Health Perspect 2014; 122(6): 553-8. doi: 10.1289/ehp.1205909.

21. Wang R, Xue D, Liu Y, Liu P, Chen H. The relationship between air pollution and depression in China: is neighbourhood social capital protective? Int J Environ Res Public Health 2018; 15(6): 1160. doi: 10.3390/ ijerph15061160.

22. Naarding P, Schoevers RA, Janzing JG, Jonker C, Koudstaal PJ, Beekman AT. A study on symptom profiles of late-life depression: the influence of vascular, degenerative and inflammatory risk-indicators. J Affect Disord 2005; 88(2): 155-62. doi: 10.1016/j.jad.2005.07.002.

23. Miller KA, Siscovick DS, Sheppard L, Shepherd K, Sullivan $\mathrm{JH}$, Anderson GL, et al. Long-term exposure to air pollution and incidence of cardiovascular events in women. $\mathrm{N}$ Engl J Med 2007; 356(5): 447-58. doi: 10.1056/NEJMoa054409.

24. Ard K, Colen C, Becerra M, Velez T. Two mechanisms: the role of social capital and industrial pollution exposure in explaining racial disparities in self-rated health. Int J Environ Res Public Health 2016; 13(10):1025. doi: 10.3390/ ijerph13101025.

25. Kent ST, McClure LA, Crosson WL, Arnett DK, Wadley VG, Sathiakumar N. Effect of sunlight exposure on cognitive function among depressed and non-depressed participants: a REGARDS cross-sectional study. Environ Health 2009; 8: 34. doi: 10.1186/1476-069x-8-34.

26. Benedetti F, Colombo C, Barbini B, Campori E, Smeraldi E. Morning sunlight reduces length of hospitalization in bipolar depression. J Affect Disord 2001; 62(3): 221-3. doi: 10.1016/s0165-0327(00)00149-x.

27. Zhang X, Zhang X, Chen X. Happiness in the air: how does a dirty sky affect mental health and subjective well-being? J Environ Econ Manage 2017; 85: 81-94. doi: 10.1016/j. jeem.2017.04.001.

28. Lin GZ, Li L, Song YF, Zhou YX, Shen SQ, Ou CQ. The impact of ambient air pollution on suicide mortality: a case-crossover study in Guangzhou, China. Environ Health 2016; 15(1): 90. doi: 10.1186/s12940-016-0177-1.

29. Kim C, Jung SH, Kang DR, Kim HC, Moon KT, Hur NW, et al. Ambient particulate matter as a risk factor for suicide. Am J Psychiatry 2010; 167(9): 1100-7. doi: 10.1176/appi. ajp.2010.09050706.

30. Wong CM, Yang L, Thach TQ, Chau PY, Chan KP, Thomas GN, et al. Modification by influenza on health effects of air pollution in Hong Kong. Environ Health Perspect 2009; 117(2): 248-53. doi: 10.1289/ehp.11605.

31. Min JY, Kim HJ, Min KB. Long-term exposure to air pollution and the risk of suicide death: a population-based cohort study. Sci Total Environ 2018; 628-629: 573-9. doi: 10.1016/j.scitotenv.2018.02.011.

32. Calderón-Garcidueñas L, Solt AC, Henríquez-Roldán C, Torres-Jardón R, Nuse B, Herritt L, et al. Long-term air pollution exposure is associated with neuroinflammation, an altered innate immune response, disruption of the blood-brain barrier, ultrafine particulate deposition, and accumulation of amyloid beta- 42 and alpha-synuclein in children and young adults. Toxicol Pathol 2008; 36(2): 289310. doi: $10.1177 / 0192623307313011$.

33. Genc S, Zadeoglulari Z, Fuss SH, Genc K. The adverse effects of air pollution on the nervous system. J Toxicol 2012; 2012: 782462. doi: 10.1155/2012/782462.

34. Yao G, Yue H, Yun Y, Sang N. Chronic SO2 inhalation above environmental standard impairs neuronal behavior and represses glutamate receptor gene expression and memory-related kinase activation via neuroinflammation in rats. Environ Res 2015; 137: 85-93. doi: 10.1016/j. envres.2014.11.012.

35. Li H, Han M, Guo L, Li G, Sang N. Oxidative stress, endothelial dysfunction and inflammatory response in rat heart to $\mathrm{NO}_{2}$ inhalation exposure. Chemosphere 2011; 
82(11): 1589-96. doi: 10.1016/j.chemosphere.2010.11.055.

36. Ji X, Han M, Yun Y, Li G, Sang N. Acute nitrogen dioxide (NO2) exposure enhances airway inflammation via modulating Th1/Th2 differentiation and activating JAKSTAT pathway. Chemosphere 2015; 120: 722-8. doi: 10.1016/j.chemosphere.2014.10.039.

37. de Oliveira MR, Silvestrin RB, Mello E Souza T, Moreira JC. Oxidative stress in the hippocampus, anxiety-like behavior and decreased locomotory and exploratory activity of adult rats: effects of sub acute vitamin A supplementation at therapeutic doses. Neurotoxicology 2007; 28(6): 1191-9. doi: 10.1016/j.neuro.2007.07.008.

38. Patki G, Solanki N, Atrooz F, Allam F, Salim S. Depression, anxiety-like behavior and memory impairment are associated with increased oxidative stress and inflammation in a rat model of social stress. Brain Res 2013; 1539: 73-86. doi: 10.1016/j.brainres.2013.09.033.

39. Dorado-Martínez C, Paredes-Carbajal C, Mascher D, Borgonio-Pérez G, Rivas-Arancibia S. Effects of different ozone doses on memory, motor activity and lipid peroxidation levels, in rats. Int J Neurosci 2001; 108(3-4): 149-61. doi: 10.3109/00207450108986511. 